\title{
Reported Practice Patterns Among Family Physicians with a Geriatrics Certificate of Added Qualifications
}

\author{
Lars E. Peterson, MD, PhD, Anneli Cochrane, MPH, Andrew W. Bazemore, MD, MPH, \\ and Stephen Petterson, $\mathrm{PhD}$
}

Practice patterns of family physicians with additional certification are unknown but are important to workforce planners and policymakers, who may presume that all family physicians provide primary care to patients of all ages. We found that nearly half of family medicine geriatricians self-report practicing primarily geriatric medicine. (J Am Board Fam Med 2015;28:314-315.)

Keywords: Geriatrics, Health Policy

Because of their broad training and generalist orientation, family physicians are the largest provider of ambulatory care in the United States. ${ }^{1}$ Discussions of current and projected shortages of primary care physicians often assume that each physician is fully engaged in clinical work and provides the full spectrum of primary care. ${ }^{2}$ However, many family physicians tailor their practices to fit the needs of their community and their personal interests. ${ }^{3}$ American Board of Family Medicine (ABFM) Diplomates can obtain Certificates of Added Qualification (CAQs) in 5 subspecialties; however, the percentage of clinical effort spent providing specialized or primary care by CAQ holders is unknown. Therefore, our objective was to determine the percentage of time Geriatrics CAQ holders spend providing specialized geriatric care.

We used demographic data provided by recertifying family physician geriatricians during their appli-

This article was externally peer reviewed.

From the American Board of Family Medicine, Lexington, KY (LEP, AC); and the Robert Graham Center, Washington, DC (AWB, SP).

Funding: none.

Conflict of interest: none declared.

Corresponding author: Lars E. Peterson, MD, PhD, American Board of Family Medicine, 1648 McGrathiana Pkwy, Lexington, KY 40511 (E-mail: lpeterson@theabfm.org).

\footnotetext{
See Related Commentary on Page 311.
}

cation for the ABFM Geriatrics CAQ examination from 2005 to 2013. The annual application contained a question asking for an estimate of the percentage of the time spent in geriatrics practice. We retained the Diplomate's most recent data if they sat for the examination more than once. We characterized these data by quintile using descriptive statistics. This study was approved without restrictions by the American Academy of Family Physicians Institutional Review Board.

From 2005 to 2013, 1,319 recertifying physicians applied for the ABFM Geriatrics CAQ. Over the same time period, 64,253 physicians applied for the ABFM Primary Maintenance of Certification examination. Geriatricians report spending a considerable amount of time practicing geriatrics: $24.0 \%$ of geriatricians devoted $>80 \%$ of their time to geriatrics (Figure 1). Fewer than $10 \%$ reported devoting $0 \%$ to $20 \%$ of their time in geriatric care, whereas $23.7 \%$ reported $60 \%$ to $80 \%$.

Using CAQ examination application data, we found that nearly half of family physician geriatricians primarily practice geriatric medicine. This finding has implications for workforce planning and ensuring our health care system can meet patient needs. Shortages and maldistribution of geriatricians exist in the United States, ${ }^{4}$ and geriatricians are providing valuable clinical care to often vulnerable elderly populations. The numbers reported here can also be viewed from a different perspective. Despite reporting much of their time in geriatrics, family medicine geriatri- 
Figure 1. Percentage of time spent practicing geriatric medicine by Family Medicine Geriatrics Certificate of Added Qualification Diplomates, 2005 to 2013 ( $\mathrm{n}=1,319)$.

30

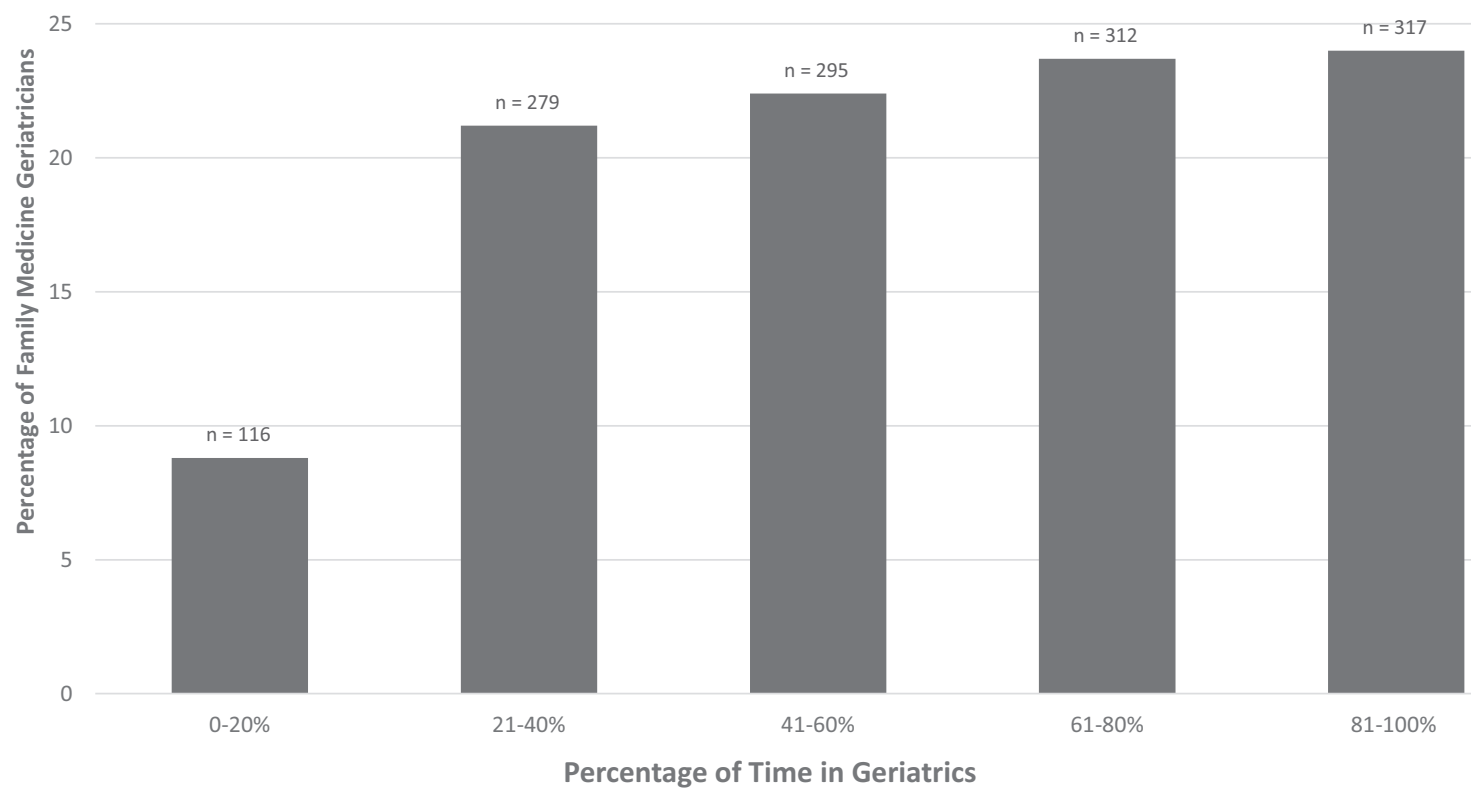

cians are still spending considerable clinical time practicing family medicine. A Medicare Payment Advisory Commission report in 2008 found that geriatricians and family physicians billed Medicare for primary care services at nearly equal percentages: $65.0 \%$ and $62.5 \%$, respectively; ${ }^{5}$ however, geriatricians likely provide most of this primary care to the elderly population. Workforce planning and policy would benefit from a further understanding of how primary care physicians specializing in geriatrics fulfill primary care for the entire population versus care for the elderly population and how best to account for variation among these providers in modeling and projection of needs.

\section{References}

1. National Ambulatory Medical Care Survey: 2010 summary tables. Atlanta: Centers for Disease Control and

Prevention; 2010. Available from: http://www.cdc.gov/ nchs/data/ahcd/namcs_summary/2010_namcs_ web_tables.pdf. Accessed March 11, 2016.

2. Petterson SM, Liaw WR, Phillips RL Jr, Rabin DL, Meyers DS, Bazemore AW. Projecting US primary care physician workforce needs: 2010-25. Ann Fam Med 2012;10:503-9.

3. Petterson S, Peterson L, Phillips R, et al. One in fifteen family physicians principally provide emergency or urgent care. J Am Board Fam Med 2014; 27:447-8.

4. Peterson LE, Bazemore A, Bragg EJ, Xierali I, Warshaw GA. Rural-urban distribution of the U.S. Geriatrics physician workforce. J Am Geriatr Soc 2011; 59:699-703.

5. Medicare Payment Advisory Commission (MedPAC). Report to the Congress: reforming the delivery system. June 2008. Available from: http://www.amcp.org/ WorkArea/DownloadAsset.aspx?id=11845. Accessed March 11, 2016. 